\title{
A Case of Cushing's Disease and Multiple Myeloma
}

\author{
Toru KinUgawa, Chiaki SHIGEMASA, Toshiaki ADACHI, \\ Yukari OKAMURA, Akio YoSHIDA and Hiroto MASHIBA
}

\begin{abstract}
A 55-year-old female of Cushing's disease associated with multiple myeloma is reported. The association of the two diseases has not been previously noted. Elevated cortisol level was controlled successfully by low doses of adrenocorticolytic agent, o,p'-DDD. However, the exacerbation of multiple myeloma was found to accompany the serum cortisol normalization. Previous reports have shown the good efficacy of combination therapy with melphalan and prednisolone for multiple myeloma. It was suggested that the decrease of endogenous cortisol level might exacerbate the patient's multiple myeloma.
\end{abstract}

Key words: Hypercortisolemia, o,p'-DDD

Although several clinical cases of Cushing's syndrome with acute leukemia have been noted $(1-3)$, case of Cushing's disease associated with multiple myeloma has not been previously reported. We present here the first case report of the association of the two diseases treated with o,p'-DDD, the adrenocorticolytic agent. The present case is of particular interest in that the exacerbation of multiple myeloma was observed to accompany the serum cortisol normalization. Considering the good efficacy of combination therapy with melphalan and prednisolone for multiple myeloma, it was suggested that the decrease of endogenous cortisol level might exacerbate the patient's multiple myeloma.

\section{CASE REPORT}

A 55-year-old female was admitted to our university hospital on January 7, 1984, complaining of lumbar pains, muscle weakness and numbness in both legs. Hypertension was noted when she was 35 years old, and she had been developing facial rounding and obesity since 1970 . On physical examination she had a plethoric moon face and central obesity. Slight hirsutism on the face and neck was present. Her blood pressure was 162/92 $\mathrm{mmHg}$.
Her height was $144 \mathrm{~cm}$, weight $47.0 \mathrm{~kg}$. Neurological examination including the eye fundi and visual fields was unremarkable except for diminished tendon reflexes, muscle weakness and hypesthesia of both legs.

No abnormalities were found in routine blood examinations or urine analysis. However, based on the presence of a Bence-Jones protein in the urine, bone marrow plasmacytosis of $15.6 \%$ (Fig. 1) and IgG- $\lambda$ monoclonal immunoglobulin in the serum (Fig. 2), a diagnosis of multiple myeloma was made. A diagnosis of Cushing's disease was established endocrinologically by the following data (Table 1): presence of elevated serum cortisol levels and increased urinary excretion of 17-hydroxycorticosteroids (17-OHCS), absence of diurnal variation of serum cortisol levels, the lack of normal suppression with $2 \mathrm{mg}$ of dexamethasone but a greater than $50 \%$ suppression with $8 \mathrm{mg}$ of dexamethasone, low responses of plasma ACTH and serum cortisol to insulin-induced hypoglycemia and an exaggerated response of plasma ACTH to lysine vasopressin.

$\mathrm{X}$-rays revealed severe osteoporosis with several compression fractures of the vertebrae (Th12, L1, L3). Bilateral adrenal ${ }^{131}$ I-adosterol high uptake

From The First Department of Internal Medicine, Tottori University School of Medicine, Yonago

Received for publication February 17, 1989

Reprint request to: Toru Kinugawa, MD, The First Department of Internal Medicine,

Tottori University, Nishimachi, 36-1, Yonago 683, Japan 


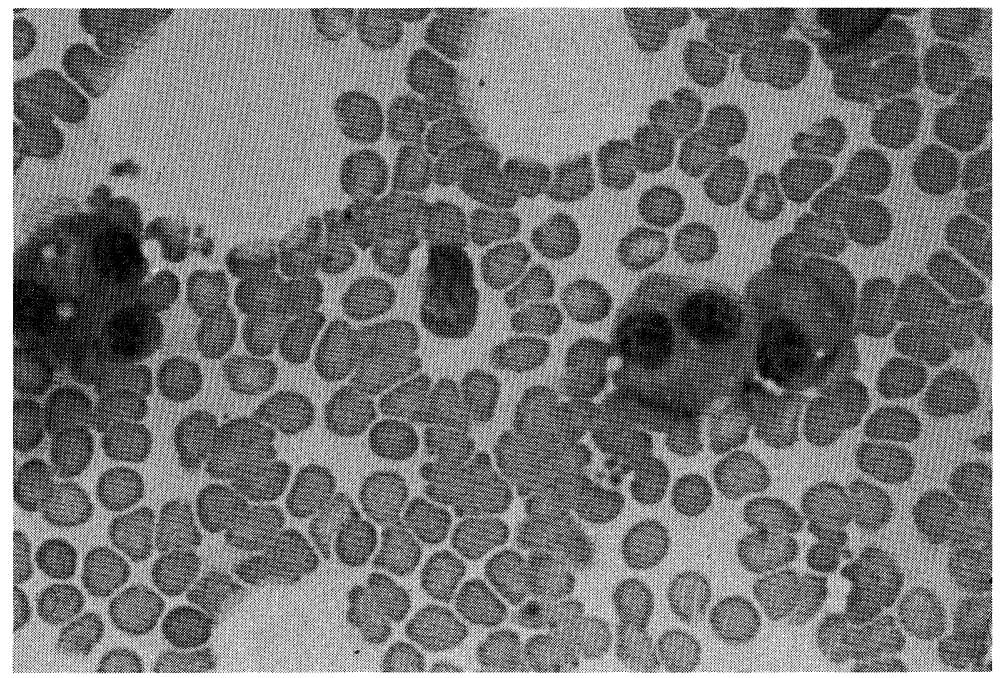

Fig. 1. Light microscopic view of bone marrow aspiration, showing binucleate plasma cells (hematoxylin and eosin stain; original magnification $\times 1,000$ ).

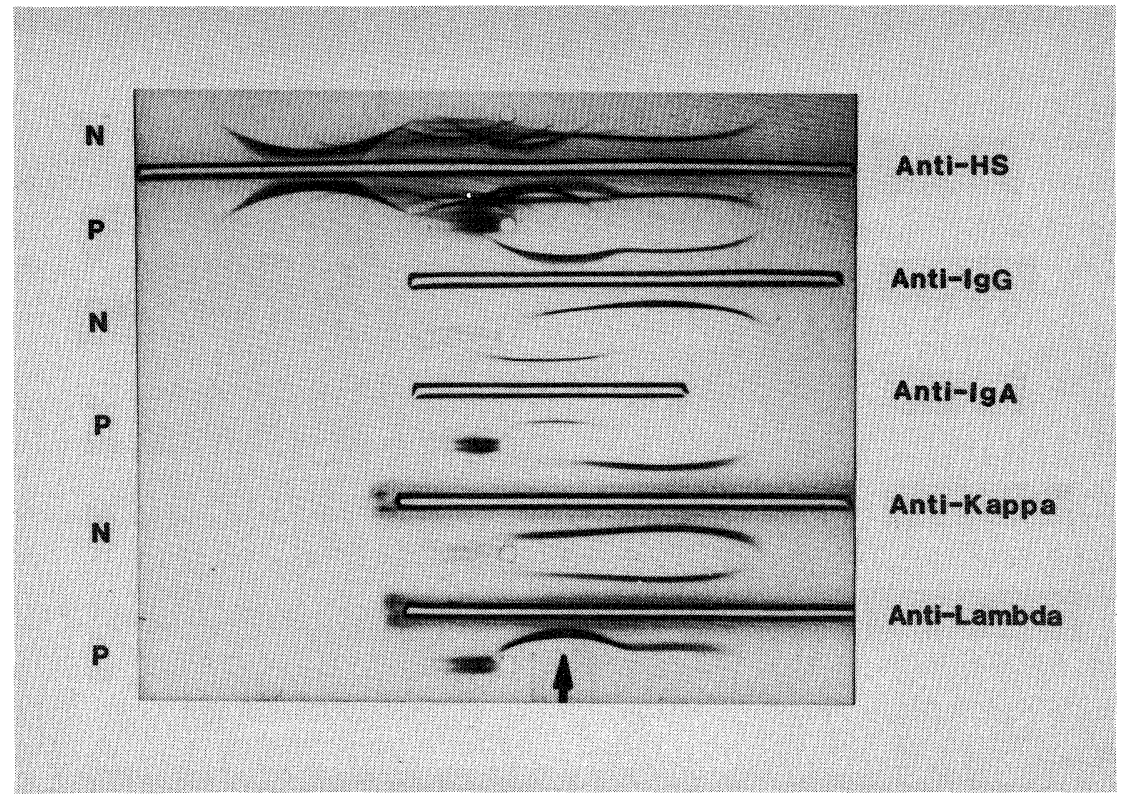

Fig. 2. Immunoelectrophoresis of serum. An arrow indicates IgG- $\lambda$ M component. N: Normal serum, P: Patient's serum, HS: Human serum.

was observed on the adrenal scintigram. Computed tomography and X-ray examination showed no sign of a pituitary tumor; however, high resolution reconstruction computed tomography of sella turcica revealed a high density spot suggesting the presence of microadenoma.
Selective venous ACTH sampling from the inferior petrosal sinus was performed to confirm the diagnosis $(6,7)$. Plasma ACTH level in the inferior petrosal sinus was significantly higher than that in the simultaneous peripheral level. The ratio of plasma ACTH concentration of the inferior petrosal 
Table 1. Results of pituitary and adrenal function on admission.

1. Basal level

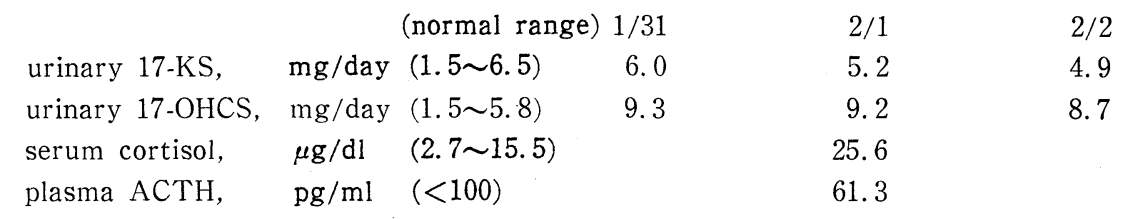

2. Diurnal variation

$\begin{array}{llrrrrrr} & & 8: 00 & 12: 00 & 16: 00 & 21: 00 & 24: 00 & 4: 00 \\ \text { plasma ACTH } & \mathrm{pg} / \mathrm{ml} & 31.2 & 28.5 & 29.9 & & 16.8 & \\ \text { serum cortisol } & \mu \mathrm{g} / \mathrm{dl} & 7.5 & 16.4 & 13.1 & 11.9 & 10.4 & 15.4\end{array}$

3. Dexamethasone suppression test

$\begin{array}{llccccccr} & & 2 / 19 & / 20 & / 21 & / 22 & / 23 & / 24 & / 25 \\ \text { urinary 17-KS } & \mathrm{mg} \text { /day } & 6.0 & 7.0 & 4.7 & 4.9 & 3.9 & 2.2 & 3.2 \\ \text { urinary 17-OHCS } & \mathrm{mg} \text { /day } & 8.7 & 10.7 & 7.0 & 5.9 & 5.6 & 3.0 & 3.5\end{array}$

4. Metyrapone test

\begin{tabular}{|c|c|c|c|c|c|c|}
\hline & & $3 / 11$ & $/ 12$ & $/ 13$ & $/ 14$ & $/ 15$ \\
\hline & & & & $3.0 \mathrm{~g}$ & & \\
\hline urinary $17-\mathrm{OHCS}$ & $\mathrm{mg} / \mathrm{day}$ & 11.5 & 10.1 & 11.4 & 13.2 & 9.1 \\
\hline
\end{tabular}

5. Insulin tolerance test*

$\begin{array}{llllllll} & & 0 & 15 & 30 & 60 & 90 & 120 \text { (min.) } \\ \text { blood sugar } & \mathrm{mg} / \mathrm{dl} & 79 & 47 & 27 & 53 & 62 & 64 \\ \text { plasma ACTH } & \mathrm{pg} / \mathrm{ml} & 15.1 & 19.0 & 18.6 & 30.6 & 23.9 & 10.1 \\ \text { serum cortisol } & \mu \mathrm{g} / \mathrm{dl} & 22.7 & 26.1 & 21.1 & 31.5 & 30.4 & 18.1\end{array}$

6. Lysine vasopressin test (Selective venous sampling)**

\begin{tabular}{llcccccl} 
& & 0 & 15 & 30 & 60 & 90 (min.) \\
plasma ACTH & $\mathrm{pg} / \mathrm{ml}$ & 15.1 & 327.7 & 284.1 & 179.6 & 112.3 (peripheral) \\
plasma ACTH & $\mathrm{pg} / \mathrm{ml}$ & 46.0 & $800<$ & $800<$ & $800<$ & 520.2 (petrosal sinus) \\
\hline
\end{tabular}

* Regular insulin 0.15 units $/ \mathrm{kg}$ body weight, intravenously adminsitered.

** Lysine vasopressin 10 units, intramuscularly administered.

sinus to that of peripheral blood $(46.0 / 15.1=3.05)$ was greater than 2.0 (Table 1). Although we recommended transsphenoidal microsurgery, the patient and her family preferred drug therapy.

After little success with bromocriptine and cyproheptadine treatment, therapy with o,p'-DDD $1 \mathrm{~g}$ daily was initiated in November 1984 . Figure 3 shows the clinical course during o,p'-DDD treatment. A rapid reduction in excretion of urinary 17-OHCS and 17-ketosteroids (17-KS) were seen in the first 2 months. However, the serum cortisol level remained unchanged. When the dosage was in- creased from 1 to $3 \mathrm{~g}$ daily and administered for another 4 weeks with a total dose of $168 \mathrm{~g}$, serum cortisol reached the normal range.

With a $3 \mathrm{~g}$ daily dose, appetite loss, nausea, vomiting and elevation of serum cholesterol, triglyceride, GOT and GPT developed. The drug had to be decreased to $1 \mathrm{~g}$ daily and then stopped with a total dose of $220 \mathrm{~g}$. The gastrointestinal symptoms disappeared 6 weeks after the discontinuation of o,p'-DDD. When the serum cortisol level reached the normal range, thirst, polydipsia, edema, hypernatremia of $151 \mathrm{mEq} / 1$ and hypokalemia of 


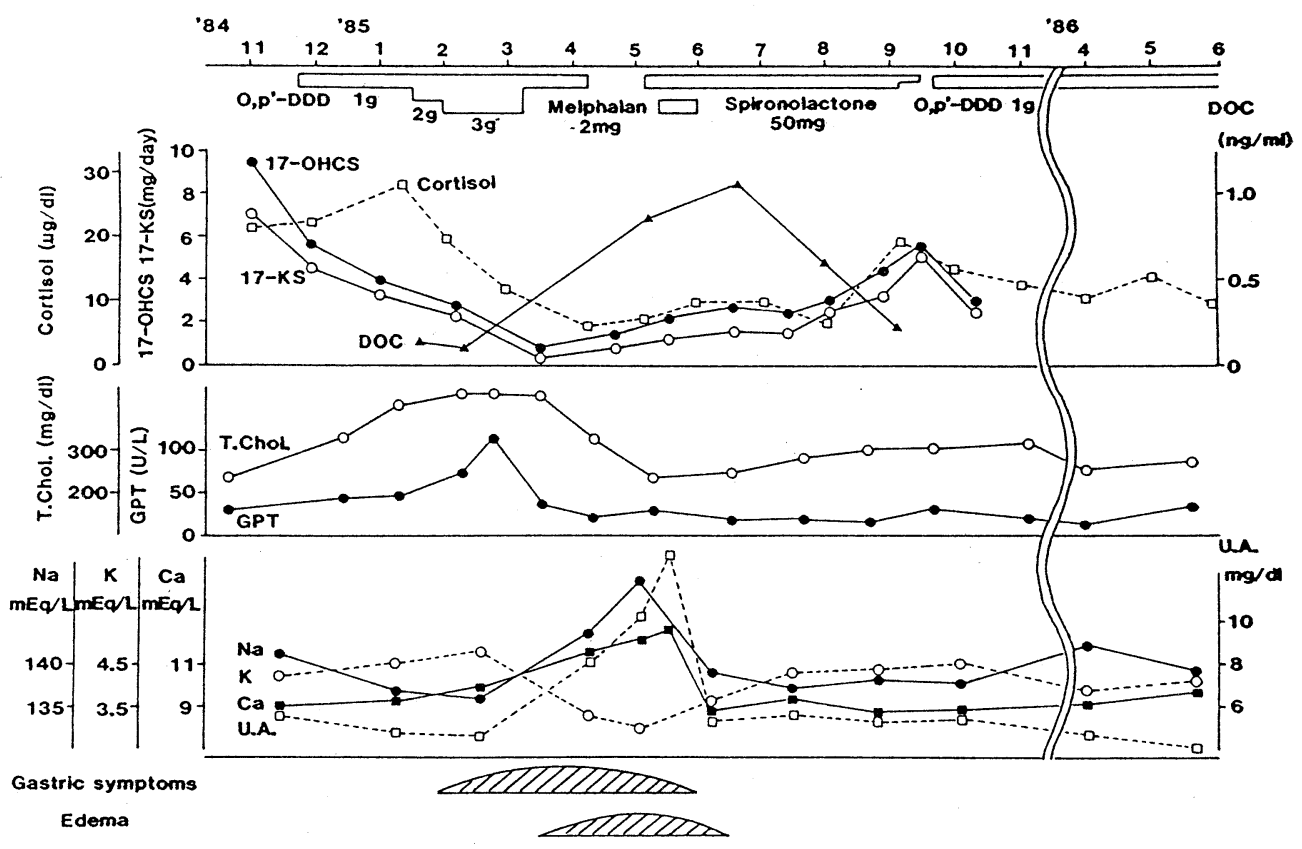

Fig. 3. Clinical course of the patient during o,p'-DDD treatment.

$3.0 \mathrm{mEq} / 1$ developed. At that time increased plasma deoxycorticosterone (DOC) level of $1.05 \mathrm{ng} / \mathrm{ml}$ (normal $[\mathrm{N}] 0.02$ to 0.20 ) and decreased plasma aldosterone concentration of $29.5 \mathrm{pg} / \mathrm{ml}$ ([N], 47 to 131 ) and PRA of $0.23 \mathrm{ng} / \mathrm{ml} / \mathrm{h}$ ( 0.5 to 2.0 ) were noted. The electrolyte abnormalities were normalized by spironolactone and plasma DOC level declined gradually to the normal range within 2 months. Simultaneously, hyperuricemia, hypercalcemia, elevation of ESR, anemia, leukocytopenia and thrombocytopenia were noted. These findings suggested the exacerbation of multiple myeloma. Two $\mathrm{mg}$ melphalan daily and $30 \mathrm{mg}$ prednisolone daily were used for a short time and these abnormalities were corrected within one month.

Six months after discontinuation of o,p'-DDD, the excretion of $17-\mathrm{OHCS}$ and $17-\mathrm{KS}$, and serum cortisol level increased so the $1 \mathrm{~g}$ o,p'-DDD daily was resumed. The patient was then maintained on a favorable clinical course. Side-effects were not noted at this dosage level.

\section{DISCUSSION}

We reported a case of Cushing's disease associated with multiple myeloma. To the best of our knowledge, the association of the two diseases has not been previously reported. Cases of Cushing's syndrome associated with acute leukemia due to ectopic ACTH secretion by the leukemic cells have been previously reported $(1,2)$. Syndrome of plasma cell dyscrasia, polyneuropathy and endocrinological disturbances $(4,5)$ also has been reported. Because our patient had plasma cell disease and polyneuropathy in addition to hypercortisolemia, the above two diseases should be taken into account as a differential diagnosis. With our patient, to confirm the diagnosis, selective ACTH sampling from the inferior petrosal sinus was performed and revealed increased concentration of plasma ACTH $(6,7)$. High resolution reconstruction computed tomography also revealed the presence of pituitary adenoma, so diagnosis of Cushing's disease associated with multiple myeloma was established. An exaggerated response to metyrapone was not observed in our patient. However, an exaggerated response is not always seen with Cushing's disease (7). The adrenocorticolytic agent, o,p'-DDD was first used in patients with adrenal carcinoma (8) and 
then in patients with Cushing's syndrome (9). Recent reports have confirmed its effectiveness in Cushing's disease (10-12). This patient's hypercortisolemia was successfully controlled by low doses of $o, p$ '-DDD. But mild liver dysfunction, increase of serum cholesterol and triglyceride levels and gastrointestinal symptoms were noted as side-effects. Simultaneously, polydipsia, edema, hypernatremia and hypokalemia developed. Both the plasma aldosterone concentration and PRA were somewhat decreased, whereas the plasma DOC level was elevated. It was considered that these symptoms and electrolyte abnormalities were caused by the excess of plasma DOC level, which was induced by the enzyme inhibiting effect of o,p'-DDD $(13,14)$. In our patient hypertension was corrected as a consequence of cortisol normalization.

Although the precise antitumor activity of prednisolone for multiple myeloma is unknown, previous reports have shown that the combination therapy with melphalan and prednisolone was more effective in increasing the number of responders $(15,16)$. Before treatment it was conceivable that cortisol normalization might give unfavorable effects for the clinical course of multiple myeloma, so we started $o, p$ '-DDD at a low dose and increased it gradually. When the serum cortisol level became normal with a $3 \mathrm{~g}$ daily dose of o,p'-DDD, the development of hyperuricemia, hypercalcemia, elevation of ESR and pancytopenia were noted. Because these findings could not all be side-effects of the o,p'-DDD $(2,17)$ and because normalization of these findings were observed after the administration of melphalan and prednisolone, it was suggested that the decrease in endogenous cortisol level might exacerbate the patient's multiple myeloma.

We reported this case not only because this is the first reported case of Cushing's disease associated with multiple myeloma, but because the effective treatment of hypercortisolemia by low doses of o,p'DDD might worsen the multiple myeloma. These observations should be considered in the treatment of Cushing's syndrome associated with multiple myeloma.

\section{REFERENCES}

1) Williams TE, Franks RC, McCallum AN: Cushing's disease in a child with lymphosarcoma and acute leukemia. Cancer 38: 1017, 1976.

2) Pfluger KH, Granse M, Groppe C, et al: Ectopic ACTH production with autoantibody formation in a patient with acute myeloblastic leukemia. N Eng J Med 305: 1632, 1981.

3) Danon M, Beckman ED, Kase JC, et al: Cushing's syndrome and acute lymphoblastic leukemia. Am J Dis Child 132: 888, 1978.

4) Takatsuki K, Yodoi J, Wakisaka G: Plasma cell dyscrasia with polyneuropathy and endocrine disorder: A new syndrome. Abstracts of the XV Congress of the International Society of Hematology, Part I, 106, 1974.

5) Crow RS: Peripheral neuritis in myelomatosis. Br Med J 2: 802, 1956.

6) Findling JW, Aron DC, Tyrrell JB, et al: Selective venous sampling for ACTH in Cushing's syndrome. Ann Intern Med 94: 647, 1981.

7) Ichihara $K$, Negoro $M$, Kuwayama A, et al: Selective venous sampling for ACTH in Cushing's disease. Neurol Med Chir (Tokyo) 24: 931, 1984.

8) Bregenstal MD, Hertz R, Lipsett $M B$, et al: Chemotherapy of adrenocortical cancer with o,p'-DDD. Ann Intern Med 53: 672, 1960.

9) Southren AL, Weisenfeld S, Laufer A, et al: Effect of $o, p$ '-DDD in a patient with Cushing's syndrome. J Clin Endocrinol Metab 21: 201, 1961.

10) Schteingart DE, Tsao HS, Taylor CI, et al: Sustained remission of Cushing's disease with mitotane and pituitary irradiation. Ann Intern Med 92: 613, 1980.

11) Orth DN, Liddle GW: Results of treatment in 108 patients with Cushing's syndrome. N Eng J Med 285: 243, 1971.

12) Luton JP, Mahoudeau JA, Bouchard PH, et al: Treatment of Cushing's disease by o,p'-DDD: Survey of 62 cases. N Eng J Med 300: 459, 1979.

13) Ojima M, Saito M, Fukuchi S: The effects of o,p'-DDD on human adrenal steroid synthesis. Folia Endocrinol Jap 60: 852, 1984.

14) Brown RD, Nicholson WE, Chick WT, et al: Effect of o,p'-DDD on human adrenal steroid $11 \beta$-hydroxylation activity. J Clin Endocrinol Metab 36: 730, 1973.

15) Alexanian R, Haut A, Khan AU, et al: Treatment for multiple myeloma. JAMA 208: 1680, 1969.

16) Costa G, Engle RL, Schilling A, et al: Melphalan and prednisolone: An effective combination for the treatment of multiple myeloma. Am J Med 59: 589, 1973.

17) Lubitz JA, Freeman L, Okun R: Mitotane use in inoperable adrenal cortical carcinoma. JAMA 223: 1109, 1973. 